\title{
Resistance to Marssonina coronaria and Alternaria alternata Apple Pathotype in the Major Apple Cultivars and Rootstocks Used in China
}

\author{
Yan Li \\ College of Horticulture, Northwest A\&F University, Yangling, Shaanxi 712100, \\ China
}

Peter M. Hirst

Department of Horticulture and Landscape Architecture, Purdue University, West Lafayette, IN 47907

\author{
Yizhen Wan', Yingjiao Liu, Qian Zhou, and Hua Gao \\ College of Horticulture, Northwest A\&F University, Yangling, Shaanxi \\ 712100, China
}

Yunzhong Guo

College of Plant Protection, Northwest A\&F University, Yangling, Shaanxi 712100, China

\section{Zhengyang Zhao, Leicun Wang, and Mingyu Han \\ College of Horticulture, Northwest A\&F University, Yangling, Shaanxi 712100, China}

Additional index words. apple breeding, disease resistance, Malus $\times$ domestica

\begin{abstract}
A comparison of field tolerance of 25 apple (Malus $\times$ domestica) cultivars and 39 apple rootstocks to the pathogens Marssonina coronaria and Alternaria alternata apple pathotype was performed. Although most apple cultivars grown in China were susceptible or highly susceptible to both pathogens causing two diseases, considerable variation in the level of resistance to both pathogens was observed. Only three cultivars, Qinguan, Jiguan, and Xiangyanghong, exhibited resistance to both pathogens. Among the rootstocks tested, 30 of $39(77 \%)$ were susceptible or highly susceptible to $M$. coronaria and $32(82 \%)$ were susceptible to the $A$. alternata apple pathotype. Four rootstocks, 'P.22', 'SH12', 'Za'ai 76', and 'Qingdao598', were resistant to both pathogens. The correlation between resistance to both pathogens was highly significant in the 74 apple cultivars and rootstocks tested suggesting common genetic resistance factors to these two pathogens. Data represented horizontal resistance in the germplasm. The resistant local germplasm should be used in disease resistance breeding programs.
\end{abstract}

China is the largest apple producer in the world, accounting for $44 \%$ of world production in 2009 (FAO, 2011). Apple production in China has increased 7 -fold in the last two decades to 31 million tonnes in 2009 (FAO, 2011; Gao et al., 2011). In recent years, many apple cultivars and rootstocks have been introduced to China from foreign countries

Received for publication 14 May 2012. Accepted for publication 30 July 2012 .

This research was supported by the Program QN 2009-13 of Northwest A\&F University, Shaanxi, China and the earmarked fund for Modern Agroindustry Technology Research System (CARS-28), the Modern Apple Industry Technology System (MATS), and the 2012-Fund for Returnees Scientists from Foreign Study in Shaanxi Province (A289021201).

${ }^{1}$ To whom reprint requests should be addressed; e-mailwyz689@hotmail.com.
(Gao et al., 2011). In addition, apple breeding has accelerated in China and several cultivars and rootstocks have been released in the last few decades (Gao et al., 2011). Currently, $\approx 90 \%$ of apple orchards are planted with wild non-dwarfing standard seedlings of species such as $M$. sieversii, $M$. baccata, and M. prunifolia used as rootstocks and cultivars as scions (Gao et al., 2011; Wan et al., 2011). A minority of orchards use "semidwarfing" trees: wild non-dwarfing seedlings as rootstocks with dwarfing interstems (e.g., 'M.26') and commercial cultivars as scions (Gao et al., 2011; Rong et al., 2011; Wan et al., 2011). The industry is transitioning to a greater use of dwarfing rootstock clones as both rootstocks and interstems (Rong et al., 2011). Researchers throughout China are developing cultivars with high quality and rootstocks with high performance, both with disease resistance (Gao et al., 2011; Wan et al., 2011). The importance of disease resistance of scions is obvious but resistance of rootstocks is also of interest. Disease-resistant rootstocks would be beneficial to nurserymen who grow rootstock liners and need to have disease-free materials. There is also some evidence that when grafted, rootstocks may be able to confer resistance to scions (Cristinzio et al., 2001; Jensen et al., 2003, 2012).

The development of such genotypes is expected to improve both fruit quality and production efficiency (Gao et al., 2011; Wan et al., 2011). However, breeding new cultivars and rootstocks is complex as a result of their highly heterozygous genetic background and long generation times (Gao et al., 2011; Janick et al., 1996; Wan et al., 2011). Therefore, careful selection of breeding parents is essential.

Marssonina coronaria (Ellis and J.J. Davis) [also known as Diplocarpon mali (Y. Harada \& Sawamura)], a causative agent of Marssonina blotch, and Alternaria alternata apple pathotype [previously known as A. mali (Roberts, 1924)], a causative agent of alternaria leaf blotch, are fungi causing the two most important diseases that devastate apple production in China (Lee et al., 2011; Shou et al., 2009; Zhao et al., 2011). In China, the annual loss of apple production caused by $M$. coronaria is $12.4 \%$ to $28.7 \%$ and to A. alternata apple pathotype is $15.9 \%$ to 30.1\% (Shou et al., 2009; Zhao et al., 2011). These two diseases primarily occur in Asian countries and seriously affect their apple industries (Lee et al., 2011; Sharma and Sharma, 2006). Symptoms of M. coronaria appear as round or oval small brown leaf spots that later become black, enlarged, and may coalesce. Eventually, leaves become chlorotic around the sites of infection and abscise. Symptoms of A. alternata apple pathotype appear as small, gray leaf spots with chlorotic margins that later extend into gray patches. Finally, the area surrounding the lesions withers and leaf abscission occurs (Harada et al., 1974; Lee et al., 2011; Sharma and Sharma, 2006; Shou et al., 2009; Tamietti and Matta, 2003; Zhao et al., 2011). In epidemic years, these two diseases can cause serious defoliation and reduce tree growth, flowering, fruit quality, and yield (Harada et al., 1974; Lee et al., 2011; Sharma and Sharma, 2006; Zhao et al., 2011).

To date, there have been few reports concerning evaluation and identification of resistance to these two fungal pathogens in apple cultivars and rootstocks commonly used in China. This study is the first to evaluate field tolerance to these two pathogens in 74 apple cultivars and rootstocks to provide basic information for the apple industry and apple disease resistance breeding programs.

\section{Materials and Methods}

Materials were obtained from the apple cultivar and rootstock repository of the Baishui Apple Experiment Station of the Northwest A\&F University, Baishui, Shaanxi Province, China. Resistance to Marssonina coronaria and Alternaria alternata apple 
pathotype in 35 apple cultivars grafted on 'M.26' rootstock and 39 rootstocks growing on their own roots was evaluated under natural conditions from 2008 to 2010 . Trees were 7 to 9 years old and planted at a spacing of $1.5 \times 2.5 \mathrm{~m}$. Each genotype had five replicates. The genotypes were classified into two groups based on their derivation: "Asian" or "Western" sources. All genotypes received the same field management such as pruning and standard insecticide and herbicide applications, but no fungicides were applied.

In Baishui, the rainy season spans from May to October with an annual rainfall of 500 to $800 \mathrm{~mm}$. Under natural conditions, symptoms of Marssonina coronaria appear in late May or early June and peak from late July to the middle of August, whereas Alternaria alternata apple pathotype symptoms have two peaks per year in the middle of June and again in the middle of September. For this reason, evaluation of resistance to these two pathogens was conducted from the middle of July and to the middle of September, when their symptoms were fully developed.

Leaf collection and measurement of disease incidence was according to $\mathrm{He}$ (1994) and Wan et al. (2007). Briefly, 150 leaves of each genotype were arbitrarily chosen for evaluation. Disease symptoms were visually rated from 0 to 7 based on the estimated proportion of leaf area affected by lesions where $0=$ no symptoms; $1=0.1 \%$ to $5.0 \%$; $2=5.1 \%$ to $15.0 \% ; 3=15.1 \%$ to $30.0 \% ; 4=$ $30.1 \%$ to $45.0 \% ; 5=45.1 \%$ to $65.0 \% ; 6=$ $65.1 \%$ to $85.0 \%$; and $7=85.1 \%$ to $100.0 \%$. These ratings were then converted into a susceptibility index (SI):

\section{Sum of (rating value}

$\times$ numbers of leaves in rating grade)

$\mathrm{SI}=\frac{\times 100}{\quad \begin{array}{l}\text { Total leaf number } \\ \quad \times \text { the highest rating value }\end{array}}$

Each genotype was classified into one of the following categories based on its SI values: extremely resistant-immune (ER), $\mathrm{SI}=$ 0 ; highly resistant (HR), $\mathrm{SI}=0.1$ to 5.0 ; resistant (R), SI = 5.1 to 25.0; susceptible (S), $\mathrm{SI}=25.1$ to 50.0 ; or highly susceptible (HS), $\mathrm{SI}=50.1$ to 100.0 .

Variance analysis and correlation coefficients of susceptibility indices between M. coronaria and A. alternata apple pathotype and between years for all genotypes were determined (Le, 2003; Wan and Fazio, 2011) using SAS software (SAS Institute Inc., Cary, NC).

\section{Results}

The cultivars evaluated differed significantly in their susceptibility to both M. coronaria $(P<0.0001)$ and A. alternata apple pathotypes $(P<0.0001)$. Of the 35 scion cultivars tested, most were susceptible to M. coronaria with $85 \%$ rated as susceptible or highly susceptible (Table 1). Similarly, 29 of the 35 cultivars $(83 \%)$ were susceptible or

Table 1. Susceptibility indices and level of resistance rating to Marssonina coronaria and Alternaria alternata apple pathotype for the major 35 apple cultivars used in China under natural conditions in 2008 to 2010 .

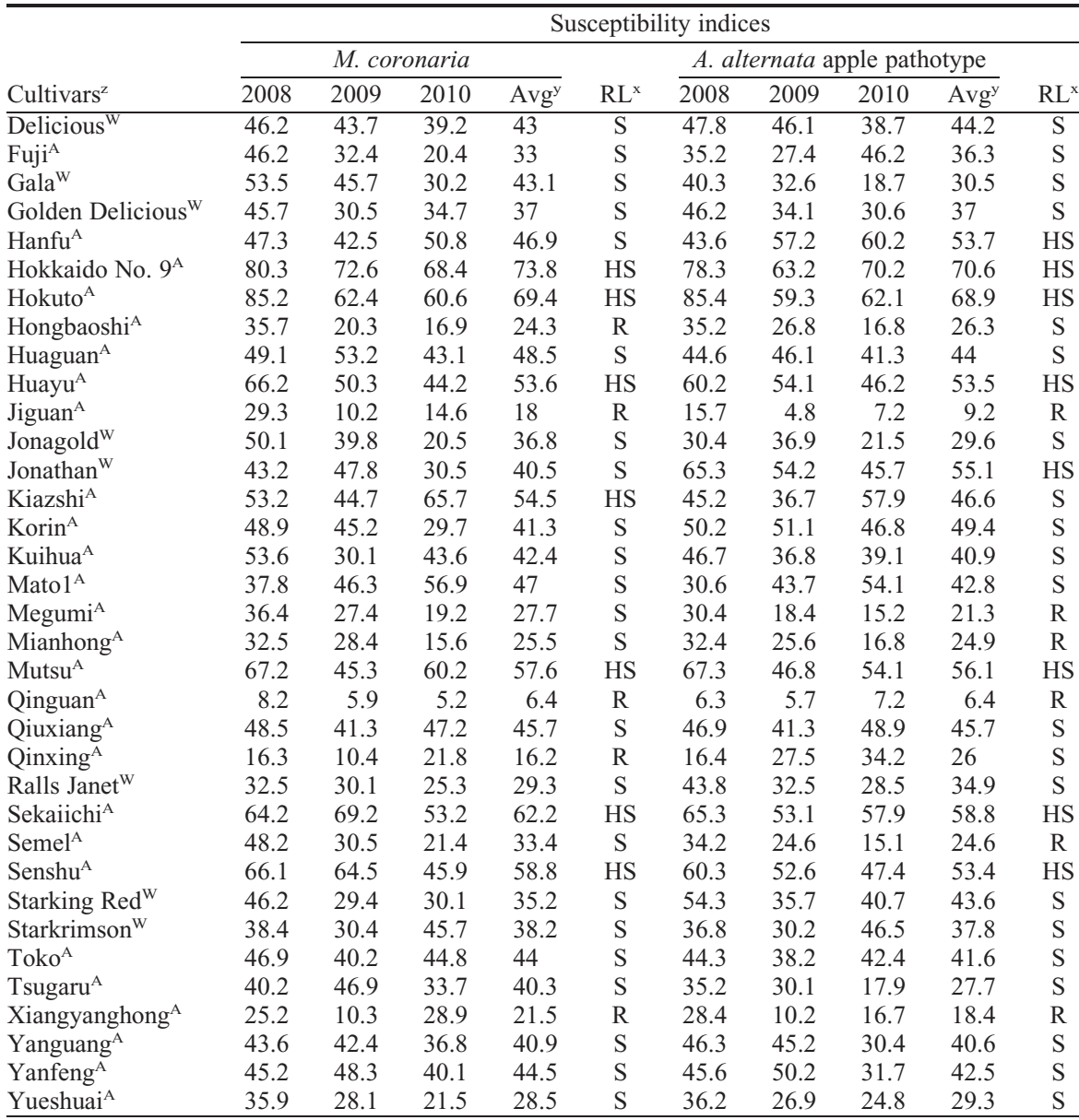

${ }^{\mathrm{z}} \mathrm{W}=$ from Western countries; $\mathrm{A}=$ from Asian countries.

${ }^{y}$ Average susceptibility index of 2008, 2009, and 2010.

${ }^{x}$ Resistance level: $\mathrm{R}=$ resistant; $\mathrm{S}=$ susceptible; $\mathrm{HS}=$ highly susceptible.

highly susceptible to the A. alternata apple pathotype (Table 1). Only three cultivars, Jiguan, Qinguan, and Xiangyanghong, were resistant to both pathogens. Among the cultivars evaluated, $74 \%$ were bred in Asian countries and $26 \%$ from Western countries (Table 1). Half of the Asian cultivars were from China. All the cultivars that exhibited resistance to either pathogen were of Chinese origin and all the Western cultivars were either susceptible or highly susceptible (Table 1).

Most rootstocks were susceptible or highly susceptible to $M$. coronaria $(77 \%)$ and $A$. alternata apple pathotypes ( $82 \%$ ) (Table 2 ). Most of the rootstocks exhibiting resistance were from Asian sources: $35 \%$ resistant to M. coronaria and $25 \%$ to the A. alternata apple pathotype. In contrast only $11 \%$ of the Western rootstocks showed resistance to either pathogen. Most rootstocks [31 of 39 (79\%)] were qualitatively similar in their susceptibility or resistance to the two pathogens. The rootstocks 'M.27', 'SH.17', 'SH.9', 'SH.18', 'A03', 'JM.7', 'S.64', and 'Qing3', exhibited qualitative differences in resistance to the two pathogens. Only four rootstocks ('P.22', 'SH.12', 'Za'ai76', and 'Qingdoa598') were rated as resistant or highly resistant to both pathogens (Table 2).
Correlation coefficients for susceptibility ratings between years were highly significant for the two pathogens demonstrating consistency from year to year for both cultivars and rootstocks (Table 3 ). There was a strong relationship between the susceptibility rating for $M$. coronaria and that for the A. alternata apple pathotype when all 74 apple cultivars and rootstocks were considered over 3 years.

\section{Discussion}

Approximately $65 \%$ of Chinese apple production is of the Fuji cultivar although it is susceptible to both $M$. coronaria and A. alternata apple pathotypes. The second most important cultivar, Qinguan (accounting for $10 \%$ Chinese apple production), exhibited resistance to both pathogens. Three cultivars (Jiguan, Qinguan, and Xiangyanghong) were resistant to both pathogens and five cultivars (Qinxing, Megumi, Mianhong, Hongbaoshi, and Semel) were resistant to one of the pathogens. All cultivars from Western countries, including 'Delicious', 'Golden Delicious', and 'Gala', were susceptible to these two pathogens. Of the Asian-derived cultivars, 20\% exhibited resistance to $M$. coronaria and $24 \%$ to the A. alternata apple pathotype (Table 1). 
Table 2. Susceptibility indices and level of resistance rating to Marssonina coronaria and Alternaria alternata apple pathotype for the major 39 apple rootstocks used in China under natural conditions in 2008 to 2010 .

\begin{tabular}{|c|c|c|c|c|c|c|c|c|c|c|}
\hline \multirow{3}{*}{$\begin{array}{l}\text { Rootstocks } \\
\text { and sources }\end{array}$} & \multicolumn{10}{|c|}{ Susceptibility indices } \\
\hline & \multicolumn{4}{|c|}{ Marssonina coronaria } & \multirow[b]{2}{*}{$\mathrm{RL}^{\mathrm{x}}$} & \multicolumn{4}{|c|}{ A. alternata apple pathotype } & \multirow[b]{2}{*}{$R L^{x}$} \\
\hline & 2008 & 2009 & 2010 & $\operatorname{Avg}^{y}$ & & 2008 & 2009 & 2010 & $\mathrm{Avg}^{\mathrm{y}}$ & \\
\hline${\mathrm{A} 03^{\mathrm{W}}}$ & 16.4 & 18.9 & 20.3 & 18.5 & $\mathrm{R}$ & 30.2 & 33.5 & 37.1 & 33.6 & $\mathrm{~S}$ \\
\hline$B 9^{W}$ & 38.9 & 33.4 & 30.4 & 34.2 & $\mathrm{~S}$ & 40.4 & 59.4 & 58.3 & 52.7 & HS \\
\hline $\mathrm{B} 118^{\mathrm{W}}$ & 58.3 & 44.2 & 58.3 & 53.6 & HS & 56.9 & 60.7 & 69.4 & 62.3 & HS \\
\hline $\mathrm{CG} 10^{\mathrm{W}}$ & 47.2 & 45.3 & 57.8 & 50.1 & HS & 48.6 & 54.8 & 57.2 & 53.5 & HS \\
\hline $\mathrm{CG} 23^{\mathrm{W}}$ & 48.2 & 46.3 & 55.6 & 50.0 & $\mathrm{~S}$ & 48.2 & 55.8 & 67.2 & 57.1 & HS \\
\hline $\mathrm{CG} 24^{\mathrm{W}}$ & 48.2 & 57.2 & 45.2 & 50.2 & HS & 45.6 & 46.7 & 58.3 & 50.2 & HS \\
\hline $\mathrm{CG} 80^{\mathrm{W}}$ & 55.8 & 44.0 & 54.2 & 51.3 & HS & 48.3 & 50.6 & 58.7 & 52.5 & HS \\
\hline $\mathrm{Cx} 3^{\mathrm{A}}$ & 32.6 & 31.8 & 28.7 & 31.0 & $\mathrm{~S}$ & 42.6 & 41.3 & 38.7 & 40.9 & $\mathrm{~S}$ \\
\hline $\mathrm{Cx} 5^{\mathrm{A}}$ & 50.3 & 42.4 & 59.3 & 50.7 & HS & 47.2 & 56.3 & 53.5 & 52.3 & HS \\
\hline GM256 & 45.7 & 31.6 & 44.6 & 40.6 & $\mathrm{~S}$ & 43.7 & 42.8 & 37.1 & 41.2 & $\mathrm{~S}$ \\
\hline Guo77-34 ${ }^{\mathrm{A}}$ & 35.4 & 27.1 & 30.2 & 30.9 & S & 30.2 & 33.5 & 37.4 & 33.7 & $\mathrm{~S}$ \\
\hline $\mathrm{JM} 7^{\mathrm{A}}$ & 12.2 & 5.5 & 7.2 & 8.3 & $\mathrm{R}$ & 28.3 & 37.2 & 23.5 & 29.7 & $\mathrm{~S}$ \\
\hline Liaozhan $2^{\mathrm{A}}$ & 37.8 & 30.9 & 45.1 & 37.9 & S & 48.3 & 58.4 & 45.8 & 50.8 & HS \\
\hline $\mathrm{M} 7^{\mathrm{W}}$ & 44.6 & 35.5 & 11.7 & 30.6 & S & 30.3 & 48.3 & 34.8 & 37.8 & $\mathrm{~S}$ \\
\hline $\mathrm{M} 9^{\mathrm{W}}$ & 55.7 & 45 & 60.3 & 53.7 & HS & 58.2 & 70.3 & 69.4 & 66.0 & HS \\
\hline $\mathrm{M} 26^{\mathrm{W}}$ & 47.0 & 30.2 & 27.8 & 37.3 & $\mathrm{~S}$ & 28.2 & 43.2 & 33.7 & 35.0 & $\mathrm{~S}$ \\
\hline $\mathrm{M} 27^{\mathrm{W}}$ & 32.4 & 26.7 & 38.4 & 32.5 & S & 28.3 & 24.3 & 19.8 & 24.1 & $\mathrm{R}$ \\
\hline $\mathrm{MAC}^{\mathrm{W}}$ & 38.2 & 30.9 & 37.3 & 35.5 & S & 59.2 & 60.1 & 58.4 & 59.2 & HS \\
\hline $\mathrm{MD} 001^{\mathrm{W}}$ & 28.5 & 29.5 & 33.6 & 30.5 & S & 30.3 & 35.6 & 40.4 & 35.4 & $\mathrm{~S}$ \\
\hline $\mathrm{MD} 002^{\mathrm{W}}$ & 52.1 & 56.2 & 50.6 & 52.9 & HS & 28.9 & 39.4 & 37.1 & 35.1 & S \\
\hline MM106 & 44.2 & 40.3 & 35.2 & 39.9 & $\mathrm{~S}$ & 34.2 & 43.2 & 38.5 & 38.6 & $\mathrm{~S}$ \\
\hline Ottawa $^{\mathrm{W}}$ & 30.5 & 30.3 & 28.5 & 29.8 & S & 20.3 & 27.4 & 30.4 & 26.0 & S \\
\hline Qing3 $^{\mathrm{A}}$ & 33.7 & 28.4 & 20.2 & 27.4 & S & 18.5 & 18.3 & 24.9 & 20.6 & $\mathrm{R}$ \\
\hline Qingdao598 & 4.1 & 5.2 & 5.5 & 4.9 & HR & 5.2 & 3.4 & 4.8 & 4.5 & HR \\
\hline $\mathrm{P} 22^{\mathrm{W}}$ & 13.6 & 7.4 & 15.2 & 12.1 & $\mathrm{R}$ & 14.3 & 17.3 & 11.5 & 14.4 & $\mathrm{R}$ \\
\hline P59 & 77.4 & 65.2 & 79.4 & 74.0 & HS & 66.2 & 79.3 & 80.1 & 75.2 & HS \\
\hline $\mathrm{P} 60^{\mathrm{W}}$ & 49.5 & 45.3 & 58.4 & 51.1 & HS & 55.3 & 69.2 & 70.1 & 64.9 & HS \\
\hline S64 ${ }^{\mathrm{A}}$ & 20.3 & 18.7 & 25.3 & 21.4 & $\mathrm{R}$ & 26.8 & 29.3 & 20.1 & 25.4 & $\mathrm{~S}$ \\
\hline $\mathrm{SH}^{\mathrm{A}}$ & 30.3 & 33.3 & 31.5 & 31.7 & $\mathrm{~S}$ & 30.5 & 29.1 & 28.1 & 29.2 & $\mathrm{~S}$ \\
\hline SH8-11 ${ }^{\mathrm{A}}$ & 35.3 & 33.6 & 37.2 & 35.4 & S & 46.3 & 45.2 & 39.2 & 43.6 & $\mathrm{~S}$ \\
\hline $\mathrm{SH}^{\mathrm{A}}$ & 34.2 & 29.7 & 30.4 & 31.4 & S & 28.3 & 22.3 & 19.4 & 23.3 & $\mathrm{R}$ \\
\hline $\mathrm{SH} 12^{\mathrm{A}}$ & 10.8 & 5.5 & 7.9 & 8.1 & $\mathrm{R}$ & 9.4 & 15.2 & 4.7 & 9.8 & $\mathrm{R}$ \\
\hline $\mathrm{SH} 17^{\mathrm{A}}$ & 8.6 & 10.8 & 15.2 & 11.5 & $\mathrm{R}$ & 38.4 & 33.5 & 41.2 & 37.7 & $\mathrm{~S}$ \\
\hline SH18 & 33.2 & 29.7 & 27.4 & 30.1 & $\mathrm{~S}$ & 28.4 & 23.1 & 33.5 & 28.3 & $\mathrm{~S}$ \\
\hline $\mathrm{SH} 28^{\mathrm{A}}$ & 25.3 & 20.1 & 27.3 & 24.2 & $\mathrm{R}$ & 30.4 & 35.6 & 41.3 & 35.8 & $\mathrm{~S}$ \\
\hline $\mathrm{SH} 29^{\mathrm{A}}$ & 47.3 & 41.2 & 39.4 & 42.6 & $\mathrm{~S}$ & 33.4 & 35.1 & 28.6 & 32.4 & $\mathrm{~S}$ \\
\hline SH38 & 48.5 & 46.3 & 55.6 & 50.1 & HS & 50.2 & 53.3 & 55.7 & 53.1 & HS \\
\hline $\mathrm{SH} 40^{\mathrm{A}}$ & 55.2 & 44.4 & 51.5 & 50.4 & HS & 50.3 & 54.2 & 43.2 & 49.2 & $\mathrm{~S}$ \\
\hline Za'ai76 $^{\mathrm{A}}$ & 0 & 0 & 2.6 & 0.9 & HR & 7.8 & 3.4 & 5.7 & 5.6 & $\mathrm{R}$ \\
\hline
\end{tabular}

${ }^{\mathrm{z}} \mathrm{W}=$ from Western countries; $\mathrm{A}=$ from Asian countries.

${ }^{\mathrm{y}}$ Average susceptibility index of 2008, 2009, and 2010.

${ }^{x}$ Resistance level: $\mathrm{HR}=$ highly resistant; $\mathrm{R}=$ resistant; $\mathrm{S}=$ susceptible; $\mathrm{HS}=$ highly susceptible.

Table 3. Correlation coefficients of average susceptibility indices of 35 cultivars and 39 rootstocks between Marssonina coronaria and Alternaria alternata apple pathotype and between years.

\begin{tabular}{|c|c|c|c|c|c|c|c|}
\hline & $2008-2009$ & $2008-2010$ & $2009-2010$ & 2008 & 2009 & 2010 & Three years \\
\hline$\overline{r^{M}}$ & $0.9036 * *$ & $0.7965 * *$ & $0.8052 * *$ & & & & \\
\hline$r^{A}$ & $0.8309 * *$ & $0.7831 * *$ & $0.8871^{* *}$ & & & & \\
\hline$r^{B}$ & & & & $0.8406^{* *}$ & $0.7612 * *$ & $0.8400 * *$ & $0.8601 * *$ \\
\hline
\end{tabular}

In previous studies, the cultivars Delicious, Fuji, Golden Delicious, Ralls Janet, Toko, Tsugaru, Mutsu, Jonagold, Jonathan, and Gala were identified as resistant to the A. alternata apple pathotype in Japan or Korea (Abe et al., 2010; Sawamura, 1990; Shin et al., 1986). Alternaria leaf blotch and Marssonina blotch were more prevalent in Shaanxi province than in northeast China owing to ecological heterogeneity and/or different virulent strains of pathogens that evolved between these regions (Liu and Huang, 2010; Shimomura et al., 1993). These factors may account for found in the SH series. Overall, rootstocks from Asian sources were more likely to be resistant than those from Western sources with $35 \%$ of Asian and $11 \%$ of Western rootstocks resistant to $M$. coronaria and $25 \%$ and $11 \%$, respectively, resistant to the A. alternata apple pathotype (Table 2). In other fruit species and diseases, rootstocks have conferred resistance on scions grafted on them (Cristinzio et al., 2001; Jensen et al., 2003, 2012), but whether resistance in the rootstocks studied here can similarly confer scion resistance is unknown.

In the present study, data were collected from 3 years to give reliable estimates of genetic resistance. Correlation coefficients $(r)$ between SI in pairs of years were highly significant (Table 3), indicating that generally resistance was reasonably consistent from year to year. However, there were a number of examples in which SI differed among years (Tables 1 and 2). Therefore, expression of resistance in some genotypes to these two pathogens may depend to some extent on environmental conditions.

M. coronaria originated in East Asia (Lee et al., 2011; Sharma and Sharma, 2006; Tamietti and Matta, 2003). A. alternata apple pathotype was first described as A. mali in the United States (Roberts, 1924). The Asian and American pathogens may produce different virulent strains and the common geographic origin of pathogen and genotype has previously been postulated (Abe et al., 2010) For all genotypes evaluated (cultivars and rootstocks), there was a higher proportion of resistance among genotypes from Asia ( $23 \%$ to $26 \%$ ) compared with genotypes from Western sources (7\%) (Tables 1 and 2). The host and pathogen may undergo a coevolutionary pathway (Mitchell-Olds and Bergelson, 2000; Richter and Ronald, 2000). This suggests that the host may develop resistance to the pathogen if the host and the pathogen originated in a similar geographic area or they coevolved under similar conditions (MitchellOlds and Bergelson 2000; Richter and Ronald, 2000). The two pathogens studied here developed in East Asia under similar environmental conditions. It is therefore not surprising that there was a significant correlation between resistances to the two pathogens. Furthermore, these data suggest that there may be common genetic resistance factors to these two pathogens. Baishui is one of the major counties for apple production in China. In most years, both of these diseases occur widely within this region. In the field, several strains of each pathogen were isolated in China, showing distinct virulence between them (Liu and Huang, 2010). Our data represent horizontal resistance in the germplasm and strongly suggest that local germplasm exhibiting resistance should be used to incorporate disease resistance into breeding programs.

\section{Literature Cited} rootstocks are the second most important rootstocks used in China and account for $15 \%$ of dwarfing rootstocks (Gao et al., 2011; Rong et al., 2011; Wan et al., 2011). Both resistant and susceptible rootstocks were
Abe, K., H. Iwanami, N. Kotoda, S. Moriya, and S. Takahashi. 2010. Evaluation of apple genotypes and Malus species for resistance to Alternaria blotch caused by Alternaria alternata 
apple pathotype using detached-leaf method. Plant Breed. 129:208-218.

Cristinzio, G., C. Iannini, G. Scaglione, and M. Boselli. 2001. Effect of rootstocks on Botrytis cinerea susceptibility of Vitis vinifera cv. Falanghina. Adv. in Hort. Sci. 14:83-86.

FAO. 2011. Production database. $<$ http://faostat.fao. org $>$.

Gao, H., Z. Dang, D. Li, L. Mei, Y. Wan, L. Wang, Z. Zhao, and G. Fazio. 2011. The history of apple breeding in People's Republic of China. Acta Hort. 903:199-205.

Harada, Y., K. Sawamura, and K. Konno. 1974. Diplocarpon mali sp. nov., the perfect state of apple blotch fungus Marssonina coronaria. Ann. Phytopath. Soc. Japan 40:412-418.

He, P.C. 1994. Viticulture. China Agriculture Press, Beijing, China.

Janick, J., J.N. Cummins, S.B. Brown, and M. Hemmat. 1996. Apple. In: Janick, J. and J.N. Moore (eds.). Fruit breeding, Volume I: Tree and tropical fruits. John Wiley \& Sons, Inc., New York, NY

Jensen, P.J., N. Halbrendt, G. Fazio, I. Makalowska, N. Altman, C. Praul, S.N. Maximova, N.K. Ngugi, R.M. Crassweller, J.W. Travis, and T.W. McNeillis. 2012. Rootstock-regulated gene expression patterns associated with fire blight resistance in apple. BMC Genomics 13:9-25.

Jensen, P.J., J. Rytter, E.A. Detwiler, J.W. Travis, and T.W. McNellis. 2003. Rootstock effects on gene expression patterns in apple tree scions. Plant Mol. Biol. 53:493-511.
Le, C.T. 2003. Introductory biostatistics. John Wiley and Sons, New York, NY.

Lee, D.H., C.G. Back, N.K.K. Win, and K.H. Choi. 2011. Biological characterization of Marssonina coronaria associated with apple blotch disease. Mycobiology 39:200-205.

Liu, J. and L.L. Huang. 2010. Identification and pathogenicity test of one-celled spore isolated from diseased leaves attacked by Marssonina coronaria. Dissertation for Master Degree, Northwest A\&F University, Yangling, Shaanxi, China.

Mitchell-Olds, T. and J. Bergelson. 2000. Biotic interactions: Genomics and co-evolution. Curr. Opin. Plant Biol. 3:273-277.

Richter, T. and P. Ronald. 2000. The evolution of disease resistance genes. Plant Mol. Biol. 42:195-204.

Roberts, J.W. 1924. Morphological characters of Alternaria mali Roberts. J. Agr. Res. 27:699-708.

Rong, Z., K. Yi, F. Yang, Z. Liu, X. Li, D. Wan, and Y. Wan. 2011. A dwarfing apple rootstock: 'Liaozhen 2'. Acta Hort. 903:169-176.

Sawamura, K. 1990. Alternaria blotch, p. 24-25. In: Jones, A.L. and H.S. Aldwinckle (eds.). Compendium of apple and pear diseases. American Phytopathological Society, St. Paul, MN.

Sharma, J.N. and P. Sharma. 2006. Studies on Marssonina coronaria (El1.\& J.J.Davis) causing Marssonina blotch of apple in Himachal Pradesh. Phytomorphology 56:61-64.

Shimomura, N., P. Park, H. Otani, M. Kodama, K. Kohmoto, and T. Ohno. 1993. Leakage sites of electrolytes from susceptible apple leaf cells treated with AM-toxin I of Alternaria alternata apple pathotype. Ann. Phytopathological Soc. Jpn. 59:563-567.

Shin, Y.U., S.J. Kang, and M.S. Kim. 1986. Studies on resistance to alternaria leaf blotch in apple cultivars. Research Reports, Horticulture, Rural Development Administration Korea Republic 28:39-45.

Shou, Y.Y., C.M. Li, Y.B. Zhao, D.M. Chen, and X.Z. Zhang. 2009. In vitro evaluation of resistance to Marssonina mali in apple. J. Fruit Sci. 26:912-914.

Tamietti, G. and A. Matta. 2003. First report of leaf blotch caused by Marssonina coronaria on apple in Italy. Plant Dis. 87:1005.

Wan, Y. and G. Fazio. 2011. Confirmation by QTL mapping of the Malus robusta ('Robusta 5') derived powdery mildew resistance gene Pll. Acta Hort. 903:95-99.

Wan, Y., D. Li, Z. Zhao, L. Mei, M. Han, H. Schwaninger, and G. Fazio. 2011. The distribution of wild apple germplasm in northwest China and its potential application for apple rootstock breeding. Acta Hort. 903: 123-141.

Wan, Y.Z., H. Schwaninger, P. He, and Y. Wang. 2007. Comparison of resistance to powdery mildew and downy mildew in Chinese wild grapes. Vitis 46:132-136.

Zhao, L., Y. Zhao, Y. Wan, and Z. Dang. 2011. A RAPD marker linked to the resistance gene to Alternaria leaf blotch (Alternaria mali Roberts) in 'Qinguan' apple. Acta Hort. 903:101-106. 